\title{
O ENVELHECIMENTO NA PERCEPÇÃO DE SUJEITOS QUINQUAGENÁRIOS
}

\author{
AGING IN THE PERCEPTION OF QUINQUAGENARY SUBJECTS
}

\author{
Alcione Oliveira Silva ${ }^{1}$ \\ Rita de Cássia Pereira Farias ${ }^{2}$ \\ Débora Pires Teixeira ${ }^{3}$
}

\section{Resumo}

O presente estudo teve por objetivo desvelar as percepções sobre o envelhecimento entre os sujeitos quinquagenários. Em uma perspectiva qualitativa, buscou-se estudar os servidores técnicos e docentes da Universidade Federal de Viçosa, Minas Gerais, com idades entre 50 e 59 anos, sendo 10 mulheres e 10 homens, aos quais foram aplicadas entrevistas semiestruturadas. A autopercepção e a percepção do envelhecimento perpassaram por visões negativas (aspectos físicos do corpo e aparência, o vestuário, as cirurgias plásticas, a saúde e a produtividade no trabalho) e positivas (acúmulo de conhecimento, a sabedoria, a experiência, a liberdade e o respeito no ambiente de trabalho) com predominância das primeiras. Conclui-se que ambos os posicionamentos (positivos e negativos) foram marcados por questões de gênero, socialmente construídas.

Palavras-chave: Gênero. Percepção Envelhecimento. Universidade Federal de Viçosa.

do

\begin{abstract}
The present study aimed to reveal perceptions about aging among quinquagenarian subjects. In a qualitative perspective, technical servers and professors of the Federal University of Viçosa, Minas Gerais, aged between 50 and 59 years were investigated, being 10 women and 10 men, to whom semi-structured interviews were applied. Self-perception and the perception of aging have undergone negative visions (physical aspects of body and appearance, clothing, plastic surgeries, health and productivity at work) and positive (accumulation of knowledge, wisdom, experience, freedom and respect in the work environment) with predominance of the former. We conclude that both positions (positive and negative) were marked by gender issues, socially constructed.
\end{abstract} Key-words: Gender. Perception of Aging. Universidade Federal de Viçosa.

\footnotetext{
${ }^{1}$ Mestre em Economia Doméstica pelo Programa de Pós-graduação em Economia Doméstica da Universidade Federal de Viçosa.E-mail: alcione.os@ufv.br

2 Doutora em Antropologia Social, Professora Associada da Universidade Federal de Viçosa, Viçosa, MG, Brasil. E-mail: rcfarias@ufv.br

${ }^{3}$ Doutora em Economia Doméstica, Professora Adjunta da Universidade Federal Rural do Rio de Janeiro, Seropédica, RJ, Brasil. E-mail: deborapires@ufrrj.br
} 


\section{INTRODUÇÃO}

Até os anos 1980, o Brasil ainda era considerado um país com população, em sua maioria, jovem. Desde então, devido à diminuição da taxa de natalidade e ao aumento da expectativa de vida nas últimas décadas, esse perfil tem gradualmente se modificado. Dados do IBGE (2015) mostram que a porcentagem de idosos passou de 9,8\%, em 2005, para 14,3\%, em 2015, representando um total de aproximadamente 28 milhões de pessoas. As projeções da Organização Mundial da Saúde (OMS, 2005) apontam que, por volta da metade deste século, a população de idosos poderá corresponder a um quinto dos brasileiros.

Conforme Almeida e Patriota (2009), as questões demográficas, embora importantes, não são suficientes para entender essa camada da população e suas necessidades diante da idade avançada, pois se trata de uma questão social em que se necessita encontrar possibilidades de assistência integral para o idoso. Afinal, embora a humanidade esteja em pleno século $\mathrm{XXI}$, tendo alcançado diversas leis que asseguram a cidadania dos idosos e avanços significativos da ciência e da tecnologia, ainda prevalecem conceitos e estereótipos negativos que fazem da velhice um período do qual as pessoas buscam escapar. $O$ termo velho é associado a perdas, doenças e decrepitude, fomentando o pensamento de que envelhecer é tornar-se feio, inútil e enfermo.

Ao longo da vida, os sujeitos vão internalizando tais concepções, chegando "à maturidade embutidos de preconceitos referentes à sua própria condição" (TEIXEIRA et al., 2015, p. 505). Segundo Yassine (2011), essa percepção do envelhecimento e a autopercepção da idade são, em parte, compostas pelas interações dinâmicas com sistemas sociais e culturais.

A literatura sobre o tema revela que os grupos etários percebem o envelhecimento de diferentes maneiras. Entre os jovens e os adultos jovens prevalece a concepção biológica e cronológica do processo de envelhecer, vinculando-o à carência e ao sofrimento (WACHELKE et al., 2008; FILADELFO; CÂNDIDO, 2016), mas também à experiência, ao conhecimento e à sabedoria (MAGNABOSCO-MARTINS; CAMARGO; BIASUS, 2009). Os adultos percebem o envelhecimento com mais medo, sendo a aposentadoria um sinônimo de inatividade e de abandono, ausência dos amigos e da família (OLIVEIRA; DUTRA; TEIXEIRA, 2010; TORRES, 2010). Os idosos, de forma geral, negam a velhice e percebem sua condição ligada à "boa idade", noção que é amplamente difundida pelos grupos de terceira idade (MAGNABOSCOMARTINS; CAMARGO; BIASUS, 2009; OLIVEIRA; DUTRA; TEIXEIRA, 2010). Entre os 
nonagenários prevalece a percepção marcada pelas questões físicas e doenças, visto que essa faixa está mais exposta a mudanças dessa natureza e, frequentemente, acessa os serviços de saúde (MURAKAMl et al., 2014).

Considerando que a variabilidade de percepções do envelhecimento auxilia na construção/solidificação, bem como na revisão dos estereótipos sobre o envelhecer, o objetivo deste estudo é identificar o pensamento social sobre envelhecimento entre pessoas quinquagenárias (50 a 59 anos), partindo de sua própria vivência e da dos outros. A delimitação desse público deve-se ao fato de os quinquagenários serem sujeitos que estão prestes a vivenciar a velhice, considerando o marcador cronológico. O romance em questão deixa transparecer uma crítica social do autor à sociedade burguesa desmascarando a romantização da condição servil da mulher. No século XIX, a sociedade de consumo se formava, impulsionada pela indústria crescente que produzia cada vez mais e estimulava o consumo, apelando para necessidades pessoais, dependência econômica e social, além de promessas de felicidade.

\section{METODOLOGIA}

O presente estudo ${ }^{4}$ assume delineamento qualitativo e de caráter descritivo. Foi realizado com funcionários da Universidade Federal de Viçosa (UFV), de ambos os sexos e com faixa etária entre 50 e 59 anos, durante o ano de 2017.

A Universidade Federal de Viçosa possuía, em 2017, um quadro de funcionários com 3711 servidores. A população da pesquisa foi formada por 1.049 servidores que apresentavam idade entre 50 e 59 anos, sendo 242 mulheres e 807 homens. A amostra foi constituída por 20 servidores que aceitaram participar voluntariamente da pesquisa: quatro técnicos (dois homens e duas mulheres) e dezesseis docentes e/ou ocupantes de cargo de chefia dentro da instituição (oito homens e oito mulheres). No total, foram pesquisados 10 homens e 10 mulheres.

Os dados foram coletados por entrevista semiestruturada, que seguiu um roteiro abordando questões sobre o envelhecimento, levando em conta a percepção de pessoas as quais ainda não atingiram a velhice oficialmente, mas estão próximas dela. As entrevistas foram realizadas de forma individual, após o aceite e assinatura do Termo de Consentimento Livre e Esclarecido (TCLE), registradas com auxílio de gravador e transcritas, posteriormente, de forma integral. As entrevistas possibilitaram não só uma análise dos aspectos verbais, mas

\footnotetext{
${ }^{4}$ Este estudo foi previamente aprovado pela comissão de ética em pesquisa da Universidade Federal de Viçosa.
} 
também dos não verbais, tais como a reação dos entrevistados e de seu comportamento a cada tema abordado.

Para análise dos resultados, inspirou-se na análise temática, com ênfase na análise de conteúdo temático-categorial, de Bardin (2000), que seguiu três etapas: (a) pré-análise (leitura flutuante); (b) exploração do material (categorização e agrupamento dos dados); (c) tratamento dos resultados e interpretação (interpretação dos resultados, inferências e discussão com autores da literatura).

As categorias de análise (aspectos físicos do corpo e aparência, o vestuário, as cirurgias plásticas, a saúde, a produtividade no trabalho, o acúmulo de conhecimento, a sabedoria, a experiência, a liberdade e o respeito no ambiente de trabalho) foram distribuídas em dois grupos: pontos positivos e negativos do envelhecimento.

\section{CARACTERIZAÇÃO DOS PARTICIPANTES DA PESQUISA}

O Quadro 1 apresenta o perfil dos entrevistados, enquanto o Quadro 2 mostra o perfil das entrevistadas.

\begin{tabular}{|c|c|c|c|c|c|c|}
\hline Entrevistado & Idade & $\begin{array}{l}\text { Estado } \\
\text { Civil }\end{array}$ & $\begin{array}{l}\text { Co- } \\
\text { residência }\end{array}$ & Formação & Cargo na UVF & Fora da UFV \\
\hline Homem 1 & 51 & Casado & $\begin{array}{l}\text { Esposa e } \\
\text { dois filhos }\end{array}$ & $\begin{array}{l}\text { Mestre em } \\
\text { Economia } \\
\text { Doméstica, UFV }\end{array}$ & $\begin{array}{l}\text { Assistente } \\
\text { Administrativo } \\
\text { (1994) }\end{array}$ & $\begin{array}{lr}\text { Jogar futebol, } \\
\text { cuidar } \\
\text { plantas/casa, ler e } \\
\text { assistir TV }\end{array}$ \\
\hline Homem 2 & 57 & $\begin{array}{l}\text { Divorcia } \\
\text { do e } \\
\text { Recasa } \\
\text { do }\end{array}$ & $\begin{array}{l}\text { Pai de 4, } \\
\text { reside com } \\
\text { um deles e } \\
\text { com esposa }\end{array}$ & $\begin{array}{l}\text { Doutor em } \\
\text { Ecologina na } \\
\text { University of } \\
\text { Southampton }\end{array}$ & $\begin{array}{l}\text { Professor do } \\
\text { Magistério } \\
\text { Superior (1987) }\end{array}$ & $\begin{array}{l}\text { Cuidar da } \\
\text { casa/jardim, ler e } \\
\text { praticar atividades } \\
\text { físicas }\end{array}$ \\
\hline Homem 3 & 54 & Casado & $\begin{array}{l}\text { Pai de } 2 \text {, } \\
\text { reside com a } \\
\text { esposa e } 1 \\
\text { deles }\end{array}$ & $\begin{array}{l}\text { Doutor em } \\
\text { Medicina } \\
\text { Veterinária e } \\
\text { pela UFRJ }\end{array}$ & $\begin{array}{l}\text { Professor do } \\
\text { Magistério } \\
\text { Superior }\end{array}$ & Jogos de futebol \\
\hline Homem 4 & 55 & Solteiro & Sozinho & $\begin{array}{l}\text { Doutor em } \\
\text { Agronomia pela } \\
\text { UFV }\end{array}$ & $\begin{array}{l}\text { Professor do } \\
\text { Magistério } \\
\text { Superior (1992) }\end{array}$ & $\begin{array}{l}\text { Ficar em casa, } \\
\text { passear em } \\
\text { cachoeiras e viajar }\end{array}$ \\
\hline Homem 5 & 57 & Solteiro & Sozinho & $\begin{array}{l}\text { Doutor em } \\
\text { Biologia Celular } \\
\text { e Estrutural, } \\
\text { UNICAMP }\end{array}$ & $\begin{array}{l}\text { Professor do } \\
\text { Magistério } \\
\text { Superior (1992) }\end{array}$ & $\begin{array}{l}\text { Fotografia, ficar em } \\
\text { casa, ler livros e } \\
\text { viajar }\end{array}$ \\
\hline Homem 6 & 51 & Solteiro & Sozinho & $\begin{array}{l}\text { Doutor em } \\
\text { Ciências } \\
\text { Biológicas na } \\
\text { UNESP }\end{array}$ & $\begin{array}{l}\text { Professor do } \\
\text { Magistério } \\
\text { Superior (2001) }\end{array}$ & $\begin{array}{l}\text { Frequentar a } \\
\text { academia e ficar } \\
\text { em casa }\end{array}$ \\
\hline Homem 7 & 50 & $\begin{array}{l}\text { Divorcia } \\
\text { do e } \\
\text { recasad } \\
0\end{array}$ & $\begin{array}{l}\text { Pai de } 3, \\
\text { reside com } 2 \\
\text { deles e com } \\
\text { esposa }\end{array}$ & $\begin{array}{l}\text { Especialista em } \\
\text { Gestão de } \\
\text { Pessoas }\end{array}$ & Técnico (1994) & $\begin{array}{l}\text { Passear com a } \\
\text { esposa/filhos, jogar } \\
\text { baralho, viajar e de } \\
\text { ver futebol }\end{array}$ \\
\hline Homem 8 & 53 & Casado & Esposa & $\begin{array}{l}\text { Doutorado em } \\
\text { Zoologia pela }\end{array}$ & $\begin{array}{l}\text { Professor do } \\
\text { Magistério }\end{array}$ & $\begin{array}{l}\text { Praticar de Tai chi } \\
\text { chuan, cuidar de }\end{array}$ \\
\hline
\end{tabular}




\begin{tabular}{|c|c|c|c|c|c|c|}
\hline & & & & $\begin{array}{l}\text { UNICAMP e } \\
\text { Pós-doutorado } \\
\text { na Alemanha e } \\
\text { Japão }\end{array}$ & Superior (1992) & $\begin{array}{l}\text { animais, ficar em } \\
\text { casa, viajar e ir a } \\
\text { bares }\end{array}$ \\
\hline Homem 9 & 51 & $\begin{array}{l}\text { Divorcia } \\
\text { do }\end{array}$ & $\begin{array}{l}\text { Pai de duas, } \\
\text { reside com } 1\end{array}$ & $\begin{array}{l}\text { Doutor em } \\
\text { Zootecnia pela } \\
\text { UNESP }\end{array}$ & $\begin{array}{l}\text { Professor do } \\
\text { Magistério } \\
\text { Superior (1994) }\end{array}$ & $\begin{array}{l}\text { Cultivar de bonsai, } \\
\text { cuidar dos } \\
\text { aquários, passeio } \\
\text { com amigos e } \\
\text { shows }\end{array}$ \\
\hline Homem 10 & 56 & Casado & $\begin{array}{l}\text { Pai de } 2 \text {, } \\
\text { reside com } 1 \\
\text { e a esposa }\end{array}$ & $\begin{array}{l}\text { Doutor em } \\
\text { Zoologia/ } \\
\text { Herpetologia } \\
\text { pelo Museu } \\
\text { Nacional do Rio } \\
\text { de Janeiro }\end{array}$ & $\begin{array}{l}\text { Professor do } \\
\text { Magistério } \\
\text { Superior (1982) }\end{array}$ & $\begin{array}{l}\text { Ficar em casa, } \\
\text { jogar futebol e } \\
\text { frequentar } \\
\text { ambientes rurais }\end{array}$ \\
\hline
\end{tabular}

Fonte: Elaboração própria, 2019.

de Janeiro

Quadro 2 - Perfil das entrevistadas

\begin{tabular}{|c|c|c|c|c|c|c|}
\hline Entrevistada & Idade & $\begin{array}{l}\text { Estado } \\
\text { Civil }\end{array}$ & $\begin{array}{l}\text { Co- } \\
\text { residência }\end{array}$ & Formação & Cargo na UVF & Fora da UFV \\
\hline Mulher 1 & 50 & Casada & $\begin{array}{l}\text { Mãe de } 2, \\
\text { reside com } \\
1 \text { deles e o } \\
\text { esposo }\end{array}$ & $\begin{array}{l}\text { Doutora em } \\
\text { Meio Ambiente e } \\
\text { Conservação da } \\
\text { Natureza }\end{array}$ & $\begin{array}{l}\text { Professora do } \\
\text { Magistério } \\
\text { Superior } \\
(1992)\end{array}$ & $\begin{array}{l}\text { Cuidar do } \\
\text { jardim/animais, } \\
\text { visitar a familiares } \\
\text { e receber } \\
\text { pessoas em casa }\end{array}$ \\
\hline Mulher 2 & 52 & Casada & $\begin{array}{l}\text { Mãe de } 2 \text {, } \\
\text { reside com } \\
1 \text { deles e o } \\
\text { esposo }\end{array}$ & $\begin{array}{l}\text { Doutora em } \\
\text { Biologia Vegetal } \\
\text { pela UNICAMP }\end{array}$ & $\begin{array}{l}\text { Professora do } \\
\text { Magistério } \\
\text { Superior } \\
(1994)\end{array}$ & $\begin{array}{l}\text { Praticar } \\
\text { atividades físicas, } \\
\text { ficar em casa e } \\
\text { viajar }\end{array}$ \\
\hline Mulher 3 & 56 & Casada & $\begin{array}{l}\text { Mãe de } 2, \\
\text { reside com } \\
1 \text { delas e o } \\
\text { esposo }\end{array}$ & $\begin{array}{l}\text { Doutora em } \\
\text { Ciência dos } \\
\text { Alimentos na } \\
\text { Cornell } \\
\text { University, EUA }\end{array}$ & $\begin{array}{l}\text { Professora do } \\
\text { Magistério } \\
\text { Superior } \\
\text { (1987) }\end{array}$ & - \\
\hline Mulher 4 & 50 & Casada & $\begin{array}{l}\text { Esposo e } 2 \\
\text { filhos }\end{array}$ & $\begin{array}{l}\text { Especialização } \\
\text { latu senso em } \\
\text { Gestão de } \\
\text { Projetos }\end{array}$ & $\begin{array}{l}\text { Técnico } \\
\text { Administrativo }\end{array}$ & $\begin{array}{l}\text { Ficar em casa } \\
\text { fazendo nada }\end{array}$ \\
\hline Mulher 5 & 53 & Divorciada & Filhos (2) & $\begin{array}{l}\text { Doutora em } \\
\text { Linguística e } \\
\text { Língua } \\
\text { Portuguesa na } \\
\text { PUC Minas }\end{array}$ & $\begin{array}{l}\text { Professora do } \\
\text { Magistério } \\
\text { Superior } \\
(2000)\end{array}$ & $\begin{array}{l}\text { Viajar, ler, ver } \\
\text { filmes, fazer } \\
\text { caminhada na } \\
\text { UFV }\end{array}$ \\
\hline Mulher 6 & 52 & Casada & $\begin{array}{l}\text { Esposo e } 2 \\
\text { filhos }\end{array}$ & $\begin{array}{l}\text { Doutora em } \\
\text { Ciências } \\
\text { Biológicas }\end{array}$ & $\begin{array}{l}\text { Professora do } \\
\text { Magistério } \\
\text { Superior } \\
(2007)\end{array}$ & $\begin{array}{l}\text { Ler, passear e } \\
\text { cursa outra } \\
\text { graduação }\end{array}$ \\
\hline Mulher 7 & 52 & Casada & $\begin{array}{l}\text { Esposo e } 1 \\
\text { filho }\end{array}$ & $\begin{array}{l}\text { Pós-doutora em } \\
\text { Agronomia }\end{array}$ & $\begin{array}{l}\text { Professora do } \\
\text { Magistério } \\
\text { Superior } \\
(2012)\end{array}$ & $\begin{array}{l}\text { Ficar em casa } \\
\text { com o } \\
\text { marido/filho, fazer } \\
\text { atividade física e } \\
\text { viajar }\end{array}$ \\
\hline Mulher 8 & 50 & Casada & Esposo & $\begin{array}{l}\text { Doutora em } \\
\text { Ciências e } \\
\text { Tecnologia de } \\
\text { Alimentos pela } \\
\text { UFV }\end{array}$ & $\begin{array}{l}\text { Técnica de } \\
\text { nível superior } \\
\text { na UFV (2009) }\end{array}$ & $\begin{array}{l}\text { Viajar, ficar em } \\
\text { casa, ir para a } \\
\text { fazenda, pescar e } \\
\text { atividade física }\end{array}$ \\
\hline Mulher 9 & 52 & Divorciada & Namorada & $\begin{array}{l}\text { Doutora em } \\
\text { Engenharia de } \\
\text { Alimentos pela } \\
\text { UNICAMP }\end{array}$ & $\begin{array}{l}\text { Professora do } \\
\text { Magistério } \\
\text { Superior } \\
(2002)\end{array}$ & $\begin{array}{l}\text { Assistir } \\
\text { programas } \\
\text { esportivos e de } \\
\text { gastronomia; } \\
\text { cozinhar e } \\
\text { frequentar } \\
\text { restaurantes } \\
\end{array}$ \\
\hline Mulher 10 & 56 & Casada & Esposo e 2 & Doutora em & Professora do & Ficar com os \\
\hline
\end{tabular}




$\begin{array}{llll}\text { filhos } & \text { Biologia } & \text { Magistério } & \text { filhos e cuidar do } \\ & \text { Molecular pela } & \text { Superior } & \text { jardim e do pomar } \\ & \text { UnB } & (1994) & \text { de casa }\end{array}$

Fonte: Elaboração própria, 2019.

No que tange o grupo dos homens, tem-se que a idade média dos participantes é 53,5, com estado civil e co-residência variados, a maioria exerce o cargo de docente e possui doutorado concluído. Quanto ao lazer, a atividade física e o termo "casa" estiveram presentes nas falas de seis deles.

Sobre o grupo das mulheres, tem-se que a idade média das participantes é 52, 2 anos. A maioria delas é casada, co-reside com filhos e esposo, exerce o cargo de docente e possui doutorado concluído. Quanto ao lazer, o termo "casa" apareceu na fala de seis delas, enquanto quatro destacaram a atividade física.

\section{PONTOS NEGATIVOS DO ENVELHECIMENTO: CONCEPÇÕES SOBRE O CORPO QUE ENVELHECE}

Nesse tópico foram agrupadas as questões que refletiram a orientação negativa acerca do envelhecimento, as quais envolveram os aspectos físicos do corpo, o vestuário, as cirurgias plásticas e a saúde. Também foram considerados os "sintomas da velhice" e o mercado de trabalho.

\section{O corpo que envelhece}

No Brasil o corpo é um capital. No entanto, não é qualquer tipo de corpo, mas o magro, jovem e belo. Esse modelo de corpo é uma riqueza, talvez a mais desejada pelos indivíduos das camadas médias e baixas, que o percebem como mecanismo que lhes confere vantagens no mercado de trabalho, no mercado do casamento e no mercado sexual (GOLDENBERG, 2007). Tendo como referência o modelo de corpo-capital, a velhice foi considerada como um momento descapitalização para os participantes da pesquisa.

Sobre o corpo que envelhece, os entrevistados de ambos os sexos mencionaram o desconforto resultante do aumento de peso com o avançar da idade. No entanto, foram as mulheres que mais retrataram a preocupação com o controle do volume corporal, bem como com a manutenção do peso, e revelaram os cuidados para preservar a "boa forma", conforme retratado nas falas das entrevistadas: 
[...] Uma dificuldade enorme para manter o peso. O que eu faço hoje é muito mais sacrificante do que antes. A questão hormonal mesmo já está mexendo. (MULHER 8)

Não quero que meu corpo continue com a tendência de aumentar o peso (MULHER 3).

Nota-se que, mesmo quando a mulher está inserida em um meio no qual se discute constantemente a igualdade entre os gêneros, como no caso da universidade, o incômodo causado pela mudança na aparência tem peso diferente sobre mulheres e homens. Tais dados reforçam que as pressões sociais em torno do corpo feminino persistem entre os quinquagenários e corroboram com o estudo de Limoeiro (2016).

Para a autora, na faixa de 40 a 59 anos, homens e mulheres afirmam que o envelhecimento é pior nas mulheres. As mulheres justificaram as desvantagens femininas em relação ao envelhecimento com genética, família, filhos, gravidez, mais responsabilidades, mais preocupações etc. (LIMOEIRO, 2016).

O depoimento das participantes sobre o aumento de peso também remete a discussões de Del Priore (2000) sobre as mudanças do corpo feminino, produzidas a partir do século XX. A autora considera que chegamos a uma era lipofóbica, em que, para ter um corpo socialmente aceitável, faz-se necessário o controle do apetite. Além do ideal de magreza, o século XX foi responsável pela exclusão da mulher velha da cena social. Com a influência do cinema e consequente exibição de rostos jovens, sensuais e maliciosos, envelhecer passou a ser associado à perda de prestígio e afastamento do convívio social. Por sua vez, a obesidade ligou-se à velhice e, como a primeira é critério determinante da feiura, juventude e magreza imperam como modelo a ser copiado (DEL PRIORE, 2000).

Mediante essa lógica, a exposição de corpos gordos e velhos - sobretudo os corpos femininos que assumem essas duas características - é amplamente censurada pela mídia e pela sociedade. Ao serem questionados sobre as possibilidades de exposição do corpo velho em nossa sociedade, tendo como referência o caso de Betty Faria ${ }^{5}$, os homens, em sua maioria (oito deles), destacaram que o corpo feminino feio, velho, flácido ou gordo não deve ser exposto, sendo compreendido como sinônimo de feiura. Os segmentos de texto a seguir demonstram essa visão.

As mulheres velhas não devem se intimidar em usar biquíni, mas as gordas têm que tomar cuidado para não usarem roupas desproporcionais aos seus corpos. O corpo feio com pelanca e muxiba ${ }^{6}$ não deve ser exposto, pois agride os olhos. (HOMEM 7)

\footnotetext{
${ }^{5}$ Em 2013, aos 71 anos, Betty Faria foi fotografada na praia do Leblon, na cidade do Rio de Janeiro, usando um biquíni. As fotos da atriz foram amplamente divulgadas na mídia e receberam diversas críticas pela exposição do seu corpo envelhecido.

${ }^{6}$ Muxiba é um modo popular de se referir à carne magra, de segunda categoria, também chamada de pelanca. Refere-se também a mulher velha e/ou muito feia.
} 
Tudo depende da pessoa, uma vez que é preciso ter senso do ridículo. A pessoa só deve exibir seu corpo se ela estiver bem, não importando a idade. Se estiver bem, ela deve se mostrar, mas se estiver muito "muxibenta" e "baleiosa", não. "Quem é jovem e muito gordinha às vezes não põe biquíni, prefere por um maiô para ficar até melhor para os olhos das outras pessoas. Acho que quando ficar velho tem que ser o mesmo tipo de pensamento. (HOMEM 10)

A visão masculina corrobora os conceitos de Foucault (1996, p. 147): "Fique nu... mas seja magro, bonito, bronzeado!" e Goldenberg (2011): apenas o corpo trabalhado, cuidado, sem marcas indesejáveis (rugas, estrias, celulites, manchas) e sem excessos (gordura, flacidez) é o único que, mesmo sem roupas, está decentemente vestido. Ao mesmo tempo, as falas reforçam as pressões sociais e o controle sobre o corpo da mulher, visto que os comentários se reportaram ao sexo feminino.

Diferentemente dos homens, em um primeiro momento, as mulheres se manifestaram contra o preconceito e enfatizaram não haver problemas na exposição do corpo velho. Em seguida, ao serem questionadas sobre a exposição pessoal, negaram a possibilidade de imitação da atriz sob a justificativa de queas pessoas mais velhas têm que ter discernimento para saber o que é adequado à sua condição de velho Ou seja, de forma contraditória, as entrevistas assumiram o discurso "seja um velho!" e se comporte como tal (GOLDENBERG, 2013).

Percebeu-se que o preconceito com relação a determinados tipos de comportamentos nem sempre é conscientemente percebido pelo sujeito. Há uma tendência em se reproduzir atitudes e sentimentos que vão sendo incutidos nas mentes sem que elas mesmas percebam. Por isso, há contradições nos discursos. Elas não criticam as idosas por usar biquínis, mas afirmam que elas não o fariam.

\section{O vestir}

Sobre o uso do vestuário em geral, o aumento do peso, os fatores hormonais ligados à menopausa, a mudança no corpo e a percepção sobre a proximidade da velhice levaram parte das mulheres a mudarem o modo de se vestir depois dos 50 anos. Para algumas entrevistadas, a roupa deve acompanhar o desenvolvimento da idade, a fim de evitar os julgamentos sociais, como serem taxadas de inadequadas e/ou de "ridículas". Contudo, esse fato não foi uma unanimidade entre as entrevistadas. Algumas revelaram que nunca aderiram à moda considerada "jovem" (curta, justa e transparente) e, por isso, não perceberam diferenças em seu vestuário. Outras relataram que mudaram suas roupas em função de um 
amadurecimento e maior conhecimento pessoal, deixando de lado os modismos e valorizando mais o seu estilo pessoal.

"[...] o meu vestuário eu mudei tudo. Assim, e eu percebo assim, sendo mais autêntica na minha forma de vestir, sabe? Antes, às vezes, eu ficava um pouco preocupada com o que estava acontecendo, como que as outras pessoas estavam vestindo. Agora não. Totalmente autêntica; visto... Quando eu vou pensar numa roupa, comprar uma roupa, eu vejo que isso está bem para mim, isso está me fazendo bem. Enfim, não é porque está sendo usado que eu vou usar. E outra coisa muito interessante, isso foi consciente, foi uma mudança assim, de preparar para entrar nos cinquenta de uma nova forma. Assim, de eu pegar meu guarda-roupa e [...] mudar tudo, pensando mais nessa coisa, no que me faz bem, no tecido que está sendo confortável para mim, eu estar mais bonita. (MULHER 8)

A preocupação com a imagem e em manterem-se adequadas ao olhar do outro foi percebida nas falas da maioria das mulheres, o que não aconteceu nos discursos produzidos pelos entrevistados. Entre os homens a questão foi recebida como humor e foi negada à preocupação com o vestuário. Dessa forma, percebe-se que a velhice marca, desigualmente, no juízo social, a mulher e o homem. Não tem o mesmo sentido nem as mesmas consequências para os homens e para as mulheres (BEAUVOIR, 1976; LE BRETON, 2012).

Bourdieu (1995) esclarece que essa diferença de tratamento se dá em função da dominação masculina. Partindo de uma concepção que constitui as mulheres como objetos simbólicos, a dominação masculina tem por efeito colocá-las em permanente estado de insegurança corporal, ou melhor, de dependência simbólica: elas existem, primeiro, pelo e para o olhar dos outros como objetos receptivos, atraentes e disponíveis (BOURDIEU, 1995). Dessa maneira, compreende-se que as diferenças apresentadas sobre a preocupação com 0 vestuário no grupo pesquisado perpassam pela questão de gênero e pela construção da feminilidade, o que inclui o vestir.

\section{As cirurgias plásticas}

Além das mudanças no vestuário, a proximidade da velhice também interferiu na percepção autorreferida da aparência e no desejo pelas cirurgias plásticas. Entre ambos os sexos, a preocupação com a aparência se faz mais presente entre as mulheres.

Sobre o desejo por cirurgias plásticas, para a maioria dos homens essa é uma questão pessoal, que independe do sexo, mas eles foram quase unânimes (nove entre dez pesquisados) em afirmar que não realizariam cirurgias plásticas para combater os efeitos do envelhecimento. Apenas um deles demonstrou desejo de realizar uma lipoaspiração, sob a alegação de melhorar o rendimento nos esportes e não pela aparência propriamente dita. 
Entre as mulheres, sete delas apoiam a utilização desse tipo de cirurgia, desde que sejam utilizadas com "bom senso", preservando os limites entre a naturalidade e o exagero. Os excertos a seguir retratam as diferentes concepções sobre gênero e cirurgia plástica:

Coloquei silicone, faço tratamento para a pele, botox e também uma cirurgia de retirada de pálpebras. Se puder, farei outras. (MULHER 7)

Não adianta fazer plástica de dois em dois anos, o que levaria a uma aparência estranha. Mas se a pessoa tem vontade de fazer uma cirurgia de vez em quando, ela deve fazer. (MULHER 10)

Devemos ter a aparência da idade que temos, mas se a pessoa sentir que não está muito bem, poderá fazer uma plástica. (MULHER 6)

Se a minha barriga crescer muito, eu farei uma lipoaspiração, mas pra não atrapalhar o meu rendimento nas atividades físicas. (HOMEM 3)

Os dados da pesquisa conferem com os achados de Limoeiro (2016). Para a autora, o desejo de realizar cirurgias plásticas esteve presente na maioria das entrevistadas (61\% das mulheres). Entre os homens, a recusa pela utilização de cirurgias plásticas foi consensual. De acordo com Goldenberg (2011), as principais razões para uma mulher brasileira fazer uma cirurgia plástica são: a diminuição dos efeitos do envelhecimento no corpo em busca de uma melhor aparência, a necessidade de corrigir um defeito físico e a aquisição de um corpo belo. A busca pelo corpo perfeito tem levado a uma ampliação do uso de botox e de próteses de silicone, como também de cirurgias plásticas (GOLDENBERG, 2011).

O Brasil é vice-recordista mundial no número de cirurgias plásticas, perdendo apenas para os Estados Unidos. Dados da Sociedade Internacional de Cirurgia Plástica e Estética (ISAPS) apontam que, em 2015, o Brasil registrou 1.224.300 casos de cirurgia plástica. Dentre os quinze tipos de cirurgias mais realizadas em 2015, seis delas estavam diretamente ligadas à técnica de rejuvenescimento, tais como cirurgia de pálpebra (143.165); lifting de sobrancelhas (31.405); lifting de mamas (80.525); lifting no pescoço (31.405); lifting no rosto (48840) e preenchimento no rosto (51.645) (LENHARO, 2016).

Para Correa (2009), tem havido um grande avanço nas pesquisas sobre a prevenção dos processos de envelhecimento, graças, principalmente, à aliança entre a medicina e a estética expressas, sobretudo no surgimento da medicina "antienvelhecimento", há mais ou menos 15 anos, nos Estados Unidos. "Os “defeitos" provocados pela ação do tempo são alvo de grande investimento do mercado de consumo, por meio de produtos que prometem ser o "elixir da juventude", para combater os efeitos do tempo nos corpos" (2009, p. 91). Segundo Lipovestsky (2000), a partir do século XXI, os termos "anti-idade", "antipeso" e a exposição do 
corpo segundo padrões de beleza passaram a ser o centro da gravidade estética em oposição às técnicas de camuflagem, além da exaltação das técnicas de prevenção.

Assim, tal como a preocupação com a decrepitude corporal e com o vestuário, a busca pela manutenção da aparência jovem foi mais perceptível no sexo feminino. Para Wolf (1992), a busca da beleza constitui uma terceira jornada de trabalho que inferioriza as mulheres. Como se não bastasse os homens não dividirem o trabalho doméstico, o que leva a mulher trabalhadora a uma dupla jornada, o investimento em beleza as leva a uma tripla. A preocupação com a beleza torna-se central na vida das mulheres, fazendo com que elas concentrem sua atenção e seus investimentos nessa área, mais do que em qualquer outra.

\section{A saúde}

Sobre a saúde do corpo que envelhece, todos os entrevistados citaram que o maior incômodo do envelhecimento estava na redução do vigor físico em contraste com a disposição da juventude, ou seja, os aspectos negativos do envelhecimento foram associados à falência do corpo. De acordo com Yassine (2011), quando os adultos começam a ter consciência do seu declínio físico e/ou cognitivo, podem atribuir essas mudanças à velhice, vinculando-o a percepções mais negativas, especialmente quando essa avaliação compara a condição atual com as fases mais jovens da sua vida.

Embora a associação negativa entre envelhecimento e desempenho corporal estivesse presente nas falas de homens e mulheres, isso se fez mais presente entre eles, que se mostraram preocupados com a questão da saúde, da diminuição da vitalidade e da virilidade, principalmente, com receio de não conseguirem um bom desempenho sexual.

As partes ruins são, sei lá, a velhice pode tirar alguns movimentos que você não vai ter mais, a agilidade, às vezes a disposição sexual, principalmente. Eu não penso muito nesse lado ruim não. (HOMEM 7)

Eu pratico esporte, eu gosto de futebol, você vê que seu corpo não tem... (HOMEM 1)

A prática de atividades físicas (futebol, academia de ginástica, thai chi chuan) foi destacada pela maioria dos entrevistados como uma das formas de lazer, representando uma preocupação com a manutenção da vitalidade, entre os homens.

$\mathrm{Na}$ fala das mulheres percebeu-se o cuidado com as práticas tidas como saudáveis. Mesmo entre as que disseram não ter percebido as mudanças em decorrência do envelhecimento, a preocupação em se manterem ativas e saudáveis foi evidenciada. Como 
sintomas de envelhecimento, as entrevistadas apontaram o ganho de peso e a presença de rugas, flacidez e manchas na pele.

Dessa maneira, a falência do corpo representou perdas para ambos os sexos, embora de maneiras diferentes, conforme destaca Limoeiro (2016). Para a autora, as mulheres maduras se importam com diversas partes do seu corpo, como os seios, barriga, rosto, nádegas e pele. Diferentemente os homens, da mesma faixa etária, que demonstraram mais apreensão com o seu pênis, revelando a preocupação masculina com a vida sexual. Nas palavras de Bitencourt (2015, p. 451), enquanto as mulheres velhas têm imagens saudosistas e positivas de seus corpos jovens e magros, os velhos comentam o que "não conseguem mais fazer" com seus corpos na atual fase da vida, tal como jogar futebol e não ter a mesmo desempenho sexual, conforme mencionaram os participantes da pesquisa.

\section{A chegada da velhice}

Questionados sobre os primeiros sintomas da velhice, homens e mulheres, em sua maioria, concordam que a chegada da velhice é de difícil percepção e que se sentem bem e confortáveis na fase da vida na qual se encontram. Essa dificuldade para perceber a velhice é corroborada por Beauvoir (1976). Para a autora, em geral, a velhice não é encarada pela sociedade como uma classe de idade bem delimitada. "É mal definido o momento em que começa a velhice, variando de acordo com as épocas e os lugares. Em parte alguma se encontram 'rituais de transição' que estabeleçam um novo estatuto” (BEAUVOIR, 1976, p. 7).

De maneira geral, a percepção do próprio envelhecimento se dá pelos sintomas físicos do corpo e pelo olhar do outro. É o outro que faz juízo de valor dos corpos, que atribui o significado tanto positivo quanto negativo, pautando-se nos valores culturais para balizar sua avaliação (LE BRETON, 2012). Dessa maneira, uma das formas mais importantes de se sentir velho, envelhecido é por meio do olhar, julgamento e representação do outro (BEAUVOIR, 1976).

Nesse sentido, seis homens balizaram sua autopercepção do envelhecimento pela avaliação da aparência alheia, tal como foi apontado no destaque que seguinte:

Quando você olha e compara, principalmente quando você vê uma pessoa que você conhece desde a infância, que você olha para ela e fala: "Oh, tá velha. Será que eu também tô?". Mas é difícil você ter essa consciência no dia a dia. Então eu acho que isso é bastante relativo quando começa a ficar velho. (HOMEM 3) 
A visão de envelhecimento alheio é compartilhada por Simone de Beauvoir, em sua obra A Velhice (1976), na qual a autora afirma que "o velho é sempre o outro" (p. 10). O velho aparece aos indivíduos ativos como uma "espécie estranha" (p.243), na qual eles não se reconhecem:

[...] em mim, é o outro que é idoso, isto é, aquele que sou para os outros e esse outro sou eu [...] A aparência de nosso corpo e de nosso rosto nos informa com mais certeza: que contraste com nossos 20 anos! Só que essa mudança se opera continuamente, e nós mal a percebemos [...]. Em nós é o outro que é velho, que a revelação de nossa idade venha dos outros (BEAUVOIR, 1976, p. 348-351)

Ainda sobre a apreciação cultural do envelhecimento, a maioria dos homens e mulheres entrevistados revelou que, no "olhar do outro", eles não aparentam sua idade cronológica e novamente negaram a velhice.

Acham que eu tenho menos. (MULHER 6)

As pessoas acham que eu aparento menos idade pelo meu jeito alegre e pelo uso de roupas coloridas, fico com um ar mais jovial. (HOMEM 3 )

A última fala é representativa das concepções dominantes do "envelhecer bem" e da juventude como um valor possível de ser conquistado em qualquer idade. Para Kertzman (2004, p.129), "a identidade do velho é ainda contrastante com a do jovem; a juventude é ainda um valor, um "bem" a ser alcançado". Se o sujeito se vê ativo, desejante, inserido, brincando, ele se considerará, no máximo, um idoso jovem, um idoso de "espírito jovem" ou, como diríamos, "um velho de alma jovem".

Nesse sentido, sete mulheres e seis homens revelaram percepções posicionamentos que negam a velhice e compactuam com o conceito do novo velho, tais como: ativo; pratico atividade física; disposto; liberdade; dentro do peso, satisfeito com o corpo etc.

Pautada na lógica fordista, a modernidade estabeleceu a "cronologização da vida", ou seja, um curso de vida ancorado na produtividade econômica e na subordinação do indivíduo aos requisitos racionalizadores da ordem social. No curso de vida moderno, três segmentos foram claramente demarcados: a juventude e a vida escolar; o mundo adulto e o trabalho; e a velhice e a aposentadoria. O "curso de vida pós-moderno" é caracterizado pela "descronologização da vida", que sugere não haver uma associação automática entre a idade e o curso de vida (DEBERT, 2004, p.56).

$\mathrm{Na}$ lógica da cronologização, o grupo que compreende os setores mais velhos tem assumido pouca relação com a representação da velhice como um período de retraimento e sobriedade (DEBERT, 2004). Pelo contrário, "são os chamados "novos velhos": sujeitos afastados do envelhecimento através da prática de atividades físicas e mentais, que lhes 
garantiriam a manutenção de suas capacidades funcionais e, em última análise, de sua juventude". Esse novo velho é o sujeito representativo da terceira idade (BARROS; CASTRO, 2002, p. 120).

De maneira semelhante ao descrito por Debert (2004) e Barros e Castro (2002), os entrevistados incorporaram a ideia de velhice vinculada à terceira idade. Concordando com a ideologia do "novo velho", os quinquagenários têm associado à chegada da velhice a manutenção da juventude (disposição, atividade, liberdade). Entretanto, as limitações físicas e cognitivas e a proximidade com a morte não estivaram ausentes dos discursos produzidos por eles.

Marcada pela dificuldade de aceitação, a velhice foi negada, principalmente, pelo grupo masculino. Segundo a pesquisa de Torres (2010), os homens adultos e as pessoas com nível mais alto de escolaridade fazem parte do grupo que vê o envelhecimento com preocupação, vinculado aos problemas de saúde e de renda. "A velhice traz para todo o indivíduo uma degradação temida. A atitude espontânea consiste em recusá-la na medida em que ela se define pela impotência, pela fealdade e pela doença” (BEAUVOIR, 1976, p. 44).

\section{O trabalho}

A visão negativa do envelhecimento também se fez presente no ambiente de trabalho. Para cinco dos homens, os velhos não têm agilidade para acompanhar os mais jovens e não dominam as tecnologias da informação, pensamentos que reforçam os estereótipos que ligam a velhice ao analfabetismo digital, à decrepitude e à inutilidade em um ambiente marcado pela competitividade e pela tecnologia, como é o caso da universidade.

Para Mercadante (1996), a identidade dos idosos é construída pela contraposição à juventude, baseada na oposição das qualidades inerentes aos jovens, como força, beleza e produtividade. Essa construção se dá na sociedade ocidental, em que os atributos adquiridos pela experiência não são valorizados, relegando ao idoso um locus de desigualdade no qual ele não encontra meios de mostrar suas qualidades. Em uma perspectiva de análise semelhante, Beauvoir (1976) aponta que a contemporaneidade tem como principal representação social aquela que vê a velhice como sinônimo de incapacidade. No sistema capitalista, o material humano só desperta interesse à medida que pode ser produtivo, sendo rejeitado à medida que se torna improdutivo.

Para Goldman (2006), essa situação se agrava pelos fatores culturais que levam ao culto de tudo o que é novo e moderno, tornando o velho, com suas limitações, um ser ridículo, 
rotulado de obsoleto e inútil. Diante desse quadro de rejeição, o sujeito quinquagenário assume como verdadeiros os valores dessa sociedade que o discrimina, transformando-o em um indivíduo marginalizado. E é exatamente dentro da produção capitalista que essa marginalização mais se evidencia, pois o modus operandi da urbanização e industrialização exige mão de obra jovem e produtiva. A fala a seguir exemplifica tal situação:

Um dos problemas que eu percebo hoje, na atualidade, é justamente na universidade: o tipo de comportamento que se tem e que se cria, que se tenta preservar, que a lei do mais forte é que prevalece, nem sempre os mais idosos conseguem ter a força dos mais jovens. $E$ o que acontece é que às vezes os mais jovens atropelam, sim, os mais idosos. (HOMEM 6)

A aposentadoria faz parte dos planos de seis dos homens entrevistados, mas esteve ausente na fala das entrevistadas. A preparação financeira figurou como plano préaposentadoria, enquanto as viagens e a dedicação às atividades de lazer e aos hobbies apareceram entre os planos pós-aposentadoria. No entanto, os entrevistados de ambos os sexos não explicitaram o momento exato de finalizar a carreia acadêmica.

Nesse sentido, a aposentadoria deixa de ser um momento de descanso e recolhimento para tornar-se um período de atividades de lazer (RODRIGUES, 2009; DEBERT, 2004).

\footnotetext{
O lazer aparece como possibilidade de evitar o envelhecimento, dentro de uma visão funcionalista, mas também compensatória, vem sob as vestes da saúde, trazendo a ideia da necessidade de manter uma vida ativa, adotar novas formas de comportamento levantando a bandeira da eterna juventude. (RODRIGUES, 2006, p. 2)
}

Três das mulheres entrevistadas afirmaram o desejo de ter uma velhice dinâmica e duas, de continuarem trabalhando. Afinal, o sujeito improdutivo está associado à velhice. Aposentar-se do trabalho pode, para alguns, significar aposentar-se também da vida ou, pelo menos, da vida ativa, em que ocorre a produção de bens, produtos e serviços.

\section{PONTOS POSITIVOS DO ENVELHECIMENTO: GANHOS INTELECTUAIS, SABEDORIA, LIBERDADE E RESPEITO}

Os aspectos positivos da velhice, para ambos os sexos, estiveram relacionados aos ganhos intelectuais e ao respeito no ambiente de trabalho. As mulheres destacaram a liberdade.

Entre os respondentes (homens e mulheres) foi valorizada a experiência e a sabedoria adquiridas com o envelhecimento, bem como a melhoria da capacidade resolutiva: 
Bom, as positivas eu diria que começam assim, pela maturidade mesmo, pela calma, pela tranquilidade em passar por certos processos, especialmente alguns problemas: você lidar melhor com isso tudo, ter mais clareza de como resolver essas várias questões. (MULHER 1)

Eu estou bastante bem. Esse ano tem sido muito pesado. Tem problemas em casa, por exemplo, e eu acho que a forma que eu estou lidando é bastante saudável, muito mais do que era antes. Eu acho que realmente eu estou tirando proveito da experiência. (HOMEM 8)

Eu acho que positivo é toda uma experiência que você adquire: saber lidar melhor com determinadas situações. Eu acho que é o aprendizado mesmo. Você vai se deparar com situações em que determinado momento você agiria de uma forma, com a experiência você vai, talvez, vendo o que para você é o mais correto e vai lidando melhor com esses conflitos que aparecem durante a vida. (HOMEM 1)

Nesses excertos é explicitada a noção do sujeito idoso "como possuidor de uma bagagem de conhecimentos, uma capacidade maior de lidar com problemas, e até mesmo um novo raciocínio. Essas seriam algumas das consequências positivas do tempo de vida que os velhos têm em comparação com os jovens" (VELOZ; NASCIMENTO-SCHULZE; CAMARGO, 1999, 499).

O perfil do público pesquisado é um fator que merece destaque. Em função do trabalho intelectual, os entrevistados tendem a perceber os ganhos do envelhecimento também na esfera do trabalho diferente do que acontece com trabalhadores braçais, para os quais o corpo representa a força de trabalho e o envelhecimento corporal dita o fim da vida laborativa.

Segundo Goldenberg (2013), os escritores, os artistas, os intelectuais teriam um papel fundamental para a construção de uma velhice livre de estereótipos: a bela velhice. Para a autora, os trabalhadores intelectuais são menos afetados pelo declínio fisiológico do que os outros, porque o trabalho intelectual, diferente do trabalho braçal, soma ganhos com o tempo.

A liberdade, a tranquilidade e o equilíbrio foram destacados como pontos positivos do envelhecimento por três entrevistadas, tal como é exemplificado a seguir:

Envelhecer é ruim, mas por outro lado, te dá uma liberdade. Um negócio impressionante, porque você enxerga as coisas com mais clareza. Você é capaz de entender situações que antes poderiam te deixar completamente desnorteada, e você lida com essas situações de uma forma muito mais tranquila. Você tem a experiência do tempo e isso é impagável. (MULHER 6)

Segundo Debert (2004) e Goldenberg (2013), a liberdade é uma palavra recorrente na fala de mulheres idosas. Após cumprirem os papéis obrigatórios de esposa e mãe, as mulheres, nessa etapa do ciclo da vida, sentem-se mais livres para dedicar seu tempo em favor da própria vida. Para Nascimento (2011), o significado da velhice como liberdade, entretanto, não as libera dos jargões de comedimento, cuidado com os julgamentos alheios, pois, mesmo estando em uma sociedade que nega a feminilidade à mulher velha, ainda assim delas são 
cobrados comportamentos adequados a sua idade, o que também inclui os cuidados com o corpo e com a beleza.

Entre as entrevistadas predominou a ideia de respeito aos mais velhos no ambiente de trabalho, que também foi compartilhada por cinco dos homens. Mencionou-se a importância da experiência, do acúmulo de conhecimentos, da sabedoria e da vivência como fatores componentes da atmosfera de respeito dentro dos ambientes acadêmicos. Tais termos são tidos como ganhos do envelhecimento e possuem reconhecimento social. Para Veloz, Nascimento-Schulze e Camargo (1999), a experiência, que se constitui em um atributo da pessoa idosa, é vista como o grande ganho da velhice.

\section{CONSIDERAÇÕES FINAIS}

$\mathrm{Na}$ visão do grupo pesquisado, os pontos negativos do envelhecimento receberam mais notoriedade. Dentre eles, destacam-se fatores que envolvem os aspectos físicos do corpo e da aparência, o vestuário, as cirurgias plásticas, a saúde e a produtividade no trabalho. Os pontos positivos do envelhecimento englobaram o acúmulo de conhecimento, a sabedoria, a experiência, a liberdade e o respeito no trabalho.

Os efeitos do envelhecimento são percebidos de maneiras diferentes por homens e mulheres. A principal queixa dos homens entrevistados foi a diminuição do vigor e da resistência física e sexual. Para as mulheres, o lado negativo da velhice também se insere em seus corpos, mas diferente dos homens, a queixa delas baseia-se no aspecto ligado à aparência, tal como o aumento de peso. O sexo feminino também se mostrou mais preocupado com o vestuário, com as cirurgias plásticas e com a saúde frente ao corpo que envelhece. Dessa maneira, conclui-se que gênero e envelhecimento se intersectam.

Sugere-se a realização de outros estudos que aprofundem as questões relacionadas às diferenças entre os gêneros e os motivos pelos quais persiste a ideia de o envelhecimento ser pior para a mulher, mesmo após as conquistas de direitos pelas feministas. Ao mesmo tempo, sugere-se que se investigue a sexualidade do homem quinquagenário frente à iminência da velhice. A preocupação com a virilidade, enquanto marca de masculinidade, esteve presente nos discursos produzidos pelos entrevistados. 


\section{REFERÊNCIAS}

ALMEIDA, Lucimêre Alves; PATRIOTA, Lucia Maria. Sexualidade na Terceira Idade: um estudo com idosas usuárias do programa Saúde da Família do bairro das Cidades - Campina Grande/PB. Revista Qualitas, v. 8, n. 1, p. 1-20, 2009.

BARDIN, Laurence. Análise de conteúdo. Lisboa: Edições 70, 2000.

BARROS, Regina Duarte Benevides de Barros; CASTRO, Adriana Miranda. Terceira Idade: o discurso dos experts e a produção do "novo velho". Estudos interdisciplinares do envelhecimento, Porto Alegre, v. 4, p. 113-124, 2002.

BEAUVOIR, Simone. A velhice. Rio de Janeiro: Nova Fronteira, 1976.

BITENCOURT, Silvana Maria. Gênero e Envelhecimento: reflexões sobre o corpo que envelheceu. Revista Kairós Gerontologia, v. 18, n. 2, p. 443-458. 2015.

BOURDIEU, Pierre. A dominação masculina. Rio de Janeiro: Bertrand Brasil, 1995.

CORREA, Mariele Rodrigues. Cartografias do envelhecimento na contemporaneidade: velhice e terceira idade. São Paulo: Cultura Acadêmica, 2009. 128 p.

DEBERT, Guita Grin. A Reinvenção da Velhice: socialização e processos de reprivatização do envelhecimento. São Paulo: Fapesp, 2004.

DEL PRIORE, Mary. Corpo a corpo com a mulher: pequena história das transformações do corpo feminino no Brasil. São Paulo: Senac, 2000.

FILADELFO, Jéssica Santos; CÂNDIDO, Aldrina da Silva Confessor. Percepção do adultojovem sobre o envelhecer. Id on line Revista Multidisciplinar e de Psicologia, v.10, n.31, s.3. p. 172-183, Out-Nov/, 2016.

FOUCAULT, Michel. Poder-corpo. In: Microfísica do poder. Graal, Rio de Janeiro, 1996. p. 81-85.

GOLDENBERG, Miriam. A bela velhice. Rio de Janeiro: Record, 2013. 128p.

9, n.2, 2011.

Corpo, envelhecimento e felicidade na cultura brasileira. Contemporânea. ed.18, v.

O corpo como capital. Estudos sobre gênero, sexualidade e moda na cultura brasileira. Barueri: Estação das Letras e Cores, 2007. 13p.

. O corpo como capital: Gênero, casamento e envelhecimento na cultura brasileira. Redige, v. 1, n. 1, 2010, p. 192-200.

GOLDMAN, Sara Nigri. Terceira idade e Serviço Social. In: REZENDE, IIma; CAVALCANTI, Ludmila Fontenele (Org). Serviço Social e Políticas Sociais. Rio de Janeiro: UFRJ, 2006. 
IBGE. Instituto Brasileiro de Geografia e Estatística. SIS 2016: 67,7\% dos idosos ocupados começaram a trabalhar com até 14 anos 2015. Disponível em: https://censo2010.ibge.gov.br/noticias-censo.html?busca=1\&id=1\&idnoticia=3326\&t=sis-201667-7-idosos-ocupados-comecaram-trabalhar-14-anos\&view=noticia. Acesso em: 08 jan. 2017.

KERTZMAN, Olga Facciolla. Velho, é o outro!: a experiência de envelhecimento de usuários do Núcleo de Atenção à Saúde do Idoso. 2004. Dissertação (Mestrado em Ciências) Programa de Pós-Graduação em Infecções e Saúde Pública da Coordenação dos Institutos de Pesquisa da Secretaria de Estado da Saúde de São Paulo, São Paulo, SP. 2004.

LE BRETON, David. Antropologia do corpo e modernidade. 2. ed. Petrópolis, RJ: Vozes, 2012.

LENHARO, Mariana. Cai número de plásticas no Brasil, mas país ainda é $2^{\circ}$ no ranking, diz estudo. G1 Noticias. Publicado em 27 de ago. 2016. Disponível em: http://g1.globo.com/bemestar/noticia/2016/08/cai-numero-de-plasticas-no-brasil-mas-pais-

ainda-e-2-no-ranking-diz-estudo.html. Acesso em: 15 jul. 2017.

LIMOEIRO, Beatrice Cavalcante. O envelhecimento e as mudanças no corpo: novas preocupações e velhas angústias. In: GOLDENBERG, Miriam (Org.). (2016). Velho é lindo! Rio de Janeiro: Civilização Brasileira, 2016. p.107-131.

LIPOVETSKY, Guilles. A Terceira Mulher: permanência e revolução do feminino. São Paulo: Companhia das Letras, 2000.

MAGNABOSCO-MARTINS, Claudia Regina M.; CAMARGO, Brígido Vizeu, BIASUS, Felipe. Representações sociais do idoso e da velhice de diferentes faixas etárias. Universitas Psychologica, v. 8, n. 3, p.831-847. Set-Dez, 2009.

MERCADANTE, Eloisa. Aspectos antropológicos do envelhecimento. In: PAPALÉO, Matheus. (Org.) Tratado de Gerontologia. São Paulo: Atheneu, 1996. p.73-6.

MURAKAMI, Emy et al. Ser Nonagenário: a percepção do envelhecimento e suas implicações. Psicologia Hospitalar, v 12, n.2, p.65-82, 2014.

NASCIMENTO, Francisca Denise Silva do. Velhice feminina: emoção na dança e coerção do papel de avó. Revista Brasileira de Sociologia da Emoção, v. 10, n. 30, p. 457-505, 2011.

OLIVEIRA, Fernanda Romano da Silva; DUTRA, Milena Carrijo Dutra, TEIXEIRA, Luzimar Raimundo. Sentido de corpo e percepção de envelhecimento de adultos e idosos. Revista Brasileira de Ciências da Saúde, v. 8, n. 25, p.32-41, Jul-Set, 2010.

OMS. Organização Mundial de Saúde. Envelhecimento Ativo: uma política de saúde. Trad. Suzana Gontijo. Brasília: Organização Pan-Americana da Saúde, 2005. 60 p.

RODRIGUES, Lizete de Souza; SOARES, Geraldo Antônio. Velho, idoso e terceira idade na sociedade contemporânea. Revista Ágora, n. 4, p. 1-29, 2006.

TEIXEIRA, Selena Mesquita de Oliveira. Reflexões acerca do estigma do envelhecer na contemporaneidade. Estudos Interdisciplinares do Envelhecimento, v. 20, n.2, p.503-515, 2015. 
TORRES, Tatiana de Lucena. Pensamento Social sobre envelhecimento, idoso e rejuvenescimento para diferentes grupos etários. 2010. Tese (Doutorado) - Centro de Filosofia e Ciências Humanas, Universidade Federal de Santa Catarina, Florianópolis, SC, 2010.

VELOZ, Maria Cristina Triguero; NASCIMENTO-SCHULZE, Clélia Maria; CAMARGO, Brigido Vizeu. Representações sociais do envelhecimento. Psicologia Reflexão e Crítica, v.12, n.2, p. 479-501, 1999.

WACHELKE, João Fernando Rech et al. Princípios organizadores da representação social do envelhecimento: dados coletados via internet. Estudos de Psicologia, v. 13, n.2, p.107-116, 2008.

WOLF, Naomi. O Mito da Beleza: como as imagens de beleza são usadas contra as mulheres. Rio de Janeiro: Rocco. 1992. 438 p.

YASSINE, Ismael Macedo Correia. A auto percepção do envelhecimento e os traços de personalidade em idosos. Dissertação (Mestrado) - Faculdade de Psicologia, Universidade de Lisboa, Lisboa, PT, 2011. 